\title{
La vida posible de poblaciones expuestas a sustancias tóxicas: desafíos para una cultura de paz
}

\section{The possible life of populations exposed to toxic substances: challenges for a culture of peace}

\author{
Stela Benítez-Leite', Ramón Corvalán²
}

\begin{abstract}
RESUMEN
La dignidad humana se reconoce como el principio ético básico que fundamenta la forma de gobierno democrática adoptada constitucionalmente en Paraguay. Este principio se entiende como autonomía o como posibilidad de diseñar un plan vital y de determinarse según características propias, requiere de ciertas condiciones materiales concretas de existencia y exige protección de la integridad física e integridad moral. Desde esta perspectiva, se reflexiona, a partir del análisis de estudios sobre poblaciones expuestas a sustancias tóxicas en diferentes contextos, acerca de la vida posible de dichas poblaciones, condicionada por la vulneración de derechos básicos, situación que plantea desafíos para promover una educación para la paz desde dichas realidades.
\end{abstract}

Palabras claves: Dignidad humana, educación para la paz, sustancias tóxicas, vulneración de derechos.

\begin{abstract}
Human dignity is recognized as the basic ethical principle that underlies the form of democratic government constitutionally adopted in Paraguay. This principle is understood as autonomy or as the possibility to design a life plan and to determine one's own choices according to one's own characteristics. It requires certain basic material conditions of existence, which include the protection of an individual's physical and moral integrity. Based on this perspective, we reflect about the possible life of populations exposed to toxic substances, using analyses of overpopulation studies exposed to toxic substances in different contexts, conditioned by the violation of basic human rights, a reality that poses challenges in the promotion of education towards a peaceful existence.
\end{abstract}

Keywords: Human dignity, education for peace, toxic substances, violation of rights.

Este artículo originalmente fue presentado como ponencia en el marco del XXI CONGRESO INTERNACIONAL DE CIENCIA Y VIDA. NO VIOLENCIA Y FRATERNIDAD: PROPUESTAS PARA UNA CULTURA DE PAZ, realizado en Asunción en el mes de Julio (15-17) del 2017. La presente versión tiene modificaciones respecto al original.

\section{LAS EVIDENCIAS}

En el año 2007 se publicó un artículo original, producto de una investigación que tuvo como objetivo describir la relación entre la exposición de los padres a plaguicidas y malformaciones congénitas en el neonato ${ }^{(1)}$. En ese momento, el estudio representó la primera investigación que abordó los efectos de los pesticidas sobre la salud humana, específicamente los defectos al nacer. La

${ }^{1}$ Facultad de Ciencias Médicas, Cátedra de Pediatría. Universidad Nacional de Asunción. Paraguay

${ }^{2}$ Miembro del Servicio Paz y Justicia, Paraguay (Serpaj-Py). Asunción Paraguay

Correspondencia: Stela Benítez-Leite; Correo: benitezleitestela@gmail.com

Conflicto de intereses: Los autores declaran no poseer conflicto de interés.

Recibido: 20/11/2017. Aceptado: 13/04/2018.

DOI: https://doi.org/10.31698/ped.45012018010 
investigación se realizó en neonatos nacidos en el Hospital Regional de Encarnación, ItapúaParaguay. El diseño fue prospectivo de casos y controles de marzo/2006 a febrero/2007. Se consideró caso a todo neonato con malformación congénita, y control a todo niño sano del mismo sexo que naciera inmediatamente después. No se incluyeron los nacimientos ocurridos fuera del hospital y se consideró exposición a cualquier contacto con agroquímicos, así como a otros factores de riesgo conocidos para malformación congénita ${ }^{(1)}$. A modo de caracterización del contexto del estudio, debe señalarse que para el departamento de Itapúa, para la época en que se realizó la investigación, la superficie sembrada de soja ocupaba el segundo lugar, comparado con otros departamentos y abarcaba aproximadamente 465.014 hectáreas durante la zafra del 2005 y 2006 con el consecuente uso masivo e intensivo de plaguicidas. Desde el 2003, para el Fondo de las Naciones Unidas para la Agricultura y la Alimentación (FAO), Paraguay pasó a formar parte de la lista de "países preocupantes" con más de 24 millones de litros de agrotóxicos empleados al año en cultivos de soja. Esta situación, había generado la necesidad de estudiar los efectos de los pesticidas sobre la salud reproductiva de la población en edad fértil de la zona de Itapúa. ${ }^{(1)}$.

Los resultados del estudio mostraron asociación entre la exposición a plaguicidas y malformaciones congénitas en neonatos nacidos en Hospital Regional de Encarnación, Paraguay ${ }^{(1)}$.

Al comparar la exposición de plaguicidas entre los casos y controles, vivir cerca de campos fumigados, vivir a una distancia $<1 \mathrm{~km}$ y almacenar agrotóxicos en la casa o habitación constituyeron factores de riesgo para malformaciones congénitas, con diferencias estadísticamente significativas. Se destaca que vivir cerca de campos fumigados tuvo dos veces más riesgo de tener hijos con malformaciones que aquellas mujeres que no vivían cerca de campos fumigados ${ }^{(1)}$.

Posteriormente, en el año 2010, se publicó otro estudio que tuvo como objetivo indagar el daño en el material genético de una población infantil expuesta potencialmente a pesticidas en el ambiente. El diseño metodológico fue de tipo observacional y transversal y participaron en el estudio 48 niños expuestos potencialmente a pesticidas y 46 niños no expuestos. Se obtuvo muestra de la mucosa bucal para determinar daño en el material genético a través de la frecuencia de micronúcleos $(\mathrm{MN})^{(2)}$.

La población infantil investigada asistía a una escuela del barrio "Los Naranjos" de la ciudad de Ñemby que se encontraba ubicada a pocos metros de un establecimiento industrial dedicado a la formulación y síntesis de químicos: insecticidas, fungicidas, herbicidas y coadyuvantes y otros productos para el agro. Instalado desde junio del año 2003, en el lugar, se definió esta situación como un factor de riesgo potencial para la salud, conforme a las conclusiones del informe final de la inspección técnica de la fábrica realizada por el Ministerio de Salud Pública y Bienestar Social, la Secretaría del Ambiente y OPS/OMS. Luego de la revisión de la capacidad de producción de la planta, las condiciones de manejo de los productos, procesamiento, almacenamiento, así como las deficiencias encontradas para el manejo y tratamiento de los residuos sólidos, líquidos y gaseosos, el equipo técnico había concluido que: “La existencia de emisiones y la eventual exposición a la comunidad constituyen un riesgo para la salud de la población y de los trabajadores" ${ }^{(2)}$.

El estudio encontró que la población potencialmente expuesta a pesticidas en el ambiente, presentaba mayor frecuencia de micronúcleos, células binucleadas, cariorrexis, picnosis que la no expuesta y la diferencia era altamente significativa, según la prueba de $t$, con una $\mathrm{p}<0,0001$ para micronúcleos y células binucleadas y también significativas para cariorrexis y picnosis. Por otro lado, también hubo mayor proporción de células en brokeneggs, cariolisis y cromatina condensada en el grupo expuesto, aunque las cifras no fueron significativas ${ }^{(2)}$.

Se utilizó como grado de exposición potencial a pesticidas en el ambiente, el tiempo de permanencia en la escuela de los niños expuestos a partir del funcionamiento de la fábrica de pesticidas. El $83 \%$ (39/47) de la muestra estudiada tuvo una exposición potencial entre 1 y 6 años, considerando que la fábrica operaba en el lugar desde hace 6 años. Así, el $40 \%$ (19/47) de la muestra estudiada tuvo un tiempo de exposición ambiental de 6 años. El 32\%(15/47) tuvo un tiempo de exposición entre 4 y 5 años y el 
127,7\%(13/47) un tiempo de exposición de1a 3 años. Actualmente la fábrica ya no se encuentra en el lugar, hecho que plantea la necesidad de realizar un seguimiento del mismo grupo así como volver a evaluar la genotoxicidad a través del análisis de micronucleos ${ }^{(2)}$.

Recientemente se publicó otro estudio sobre derechos vulnerados en población campesina expuesta al cultivo de soja transgénica ${ }^{(3)}$ que tuvo como objetivo indagar las condiciones de riesgo de exposición a pesticidas en población dedicada al cultivo de subsistencia y rodeada por cultivos OGM a través del análisis de cumplimiento de obligaciones estatales para garantizar derechos básicos. El cumplimiento de las obligaciones estatales se realizó mediante el análisis de la Constitución Nacional y la ley del control fitosanitario.

Se constató que la población campesina estudiada tiene riesgo de exposición permanente a pesticidas en un contexto de violación reiterada de derechos humanos. Las fumigaciones aéreas se efectúan sin que se tengan en cuenta las condiciones climáticas, tampoco la población es avisada ni fue capacitada en el conocimiento y manejo de agroquímicos. Se describe manejo irregular en la conservación inadecuada de envases, falta de uso de equipo adecuado de fumigación, lavado de ropas y resguardo de niños dentro del hogar durante fumigaciones masivas ${ }^{(3)}$.

Se resumió la situación de la población afectada en los siguientes términos: "Desde la perspectiva de la epidemiología crítica y conforme a la constatación de una serie de obligaciones estatales no cumplidas y que configuran, por tanto, violación de derechos, la situación de la población de la colonia San Juan, se caracteriza por la exposición permanente a plaguicidas que constituye un aspecto de un conjunto de procesos que poseen propiedades destructivas/ deteriorantes de las condiciones de vida de las familias. La existencia de esta exposición permanente configura una situación que ya no resulta una eventualidad sino como imposición de un modo de determinación, cualidad propia de la exposición permanente que supone una alta vulnerabilidad epidemiológica de la población afectada que posee escaso control sobre las condiciones de exposición. En ese conjunto de procesos se destaca la debilidad, y en varios de los derechos relevados, ausencia de la capacidad estatal de garantizar y proteger derechos básicos. La violación de los mismos es un patrón repetitivo en cuyo marco deberán comprenderse los modos que asuman la salud y la enfermedad en la población de la colonia San Juan" ${ }^{\text {(3) }}$.

Este trabajo forma parte del proyecto de investigación 14INV 180, éste es el código con el cual el Consejo Nacional de Ciencias y Tecnología (CONACYT) identificó al proyecto de investigación titulado: "Exposición potencial a plaguicidas y evaluación de daño en el ADN a través del ensayo cometa y test de micronúcleos y nivel de colinesterasa plasmática en niños de población rural", apoyado por el CONACYT. El artículo final que expone los hallazgos y discute los mismos, titulado: “Evaluación del daño al ADN en niños que residen en zonas de fumigación intensiva", próximo a publicarse, muestra que en los niños expuestos a plaguicidas se observa mayor efecto genotóxico y citotóxico comparado con los niños no expuestos ${ }^{(3)}$.

Se consideró pertinente señalar que estos hallazgos resultan coincidentes con los resultados encontrados en una serie de investigaciones desarrolladas en América Latina y Europa ${ }^{(4-10)}$. Estas son, por tanto, evidencias que indican que la exposición a plaguicidas causa daño genotóxico. El dato puede establecer las bases científicas para realizar una intervención sanitaria de carácter preventivo, sobre todo en poblaciones más vulnerables como las mujeres embarazadas y niños. Se aclara que este daño genotóxico puede iniciar los procesos de carcinogénesis, mutagénesis y teratogénesis. El cáncer resulta de la interacción entre susceptibilidad genética y exposición ambiental. Varios plaguicidas han sido caracterizados como probables carcinógenos humanos por la International Agency for Researchon Cancer ${ }^{(11,12)}$ asociados con exposición a plaguicidas en estudios epidemiológicos ${ }^{(13)}$. Se ha asociado al glifosato y sus formulaciones con el incremento de determinados tipos de neoplasias en algunos casos con alteración del equilibrio hormonal ${ }^{(14-17)}$.

\section{NOTAS SOBRE CULTURA DE PAZ}

Para interpelar a estas evidencias desde los principios 
de la Cultura de Paz, deben identificarse precisamente dichos principios que son resultados de procesos históricos y de reflexiones colectivas. Es así que en 1989, producto del Congreso Internacional sobre la Paz en la Mente de los Hombres, realizado en Yamusukro, Costa de Marfil, África, se delineó el concepto de Cultura de Paz, que ya venía tomando cuerpo en el contexto internacional. Algunas reflexiones básicas destacadas durante el Congreso fueron:

- La Paz es esencialmente el respeto a la vida.

- La Paz es el bien más preciado de la Humanidad.

- La Paz no es sólo el término de los conflictos armados.

- La Paz es un comportamiento.

- La Paz es una adhesión profunda del ser humano a los principios de libertad, justicia, igualdad y solidaridad entre todos los seres humanos.

- La Paz es también una asociación armoniosa entre la Humanidad y el medio ambiente ${ }^{(18)}$.

Posteriormente, en 1999, la Asamblea General de las Naciones Unidas, aprueba la Declaración y Programa de Acción sobre una Cultura de Paz. En el documento se hace llamamiento a todos (individuos, grupos, asociaciones, comunidades educativas, empresas e instituciones) a llevar a su actividad cotidiana un compromiso consistente basado en el respeto por todas las vidas, el rechazo a la violencia, la generosidad, el entendimiento, la preservación ambiental y la solidaridad.

En relación al respeto, el Documento hacía particular referencia a:

- Respeto pleno de los derechos humanos, de todos ellos en sus distintas generaciones, atendiendo su indivisibilidad, integralidad e interdependencia.

- Respeto, fomento e instrumentación para el ejercicio efectivo del derecho a la información de todas las personas, a la libertad de opinión y expresión, al pensamiento divergente.

- Respeto y protección del ambiente, no sólo de nuestro entorno inmediato sino pensado mundialmente.

- Respeto y aceptación de la protesta y la resistencia como instrumentos de defensa civil y de transformación social ${ }^{(18)}$.

A modo de resumen, puede señalarse que los Derechos Humanos conforman el referente ético de la Cultura de Paz, existe una relación indisoluble entre dignidad humana y Derechos Humanos y la violencia en todas sus formas y manifestaciones es antitética de la Paz, ésta no puede existir donde hay violencia.

$\mathrm{Si}$ se entiende que la cultura tiene que ver con las relaciones de poder, con las relaciones de producción y con las relaciones educativas que se dan en una sociedad determinada en un momento histórico particular; consecuentemente la Cultura de Paz, según lo planteado más arriba, supone posicionamientos específicos sobre las características, el significado y las proyecciones de dichas relaciones ${ }^{(18)}$. Al respecto, debe considerarse que "la estructura actual de las sociedadesmundo no ha surgido del predominio de políticas fundamentadas en el respeto recíproco de valores como la dignidad, la autonomía y la igual libertad de las personas de todas las culturas y latitudes, que son las políticas que ineludiblemente han de caracterizar a las sociedades que luchen efectivamente contra la injusticia [...] al contrario, el orden mundial del tiempo presente ha de ser preferentemente interpretado como un orden injusto" ${ }^{\prime(19)}$.

Es en el marco de esta tensión entre los principios de la Cultura de Paz y la estructura actual de las sociedades-mundo, que se plantea situar el análisis de la situación de las poblaciones expuestas a sustancias tóxicas desde una perspectiva bioética.

\section{LAS VIDAS DAÑADAS}

En Marcos de Guerra. Las vidas lloradas, Judith Butler señala que "una vida concreta no puede aprehenderse como dañada o perdida si antes no es aprehendida como viva. Si ciertas vidas no se califican como vidas dentro de ciertos marcos epistemológicos, tales vidas nunca se considerarán vividas ni perdidas en el sentido pleno de ambas palabras ${ }^{\prime(20)}$.

Desde este planteo, se considera legítimo interrogarse acerca de una situación que se reitera en las investigaciones comentadas anteriormente: en todas ellas se encuentran poblaciones expuestas, sin protección alguna, a sustancias tóxicas, y cuando dichas sustancias forman parte de un paquete tecnológico asociado con el monocultivo de la soja transgénica, incluso, se registran una serie de violaciones de derechos humanos básicos, sin que las autoridades responsables de garantizar el cumplimiento de normas 
mínimas actúen para proteger dichos derechos constitucionalmente reconocidos.

Una investigación sobre conflictos en territorios rurales en Paraguay identificó, entre agosto del 2013 y agosto del 2015, 43 casos de criminalización: más de $60 \%$ de los mismos vinculados a la lucha por la tierra, y cerca de $40 \%$ a la lucha contra los agronegocios. En estos conflictos suelen llegarse a enfrentamientos físicos directos, con la Policía Nacional o con guardias privados contratados por los empresarios del agronegocio. La investigación constató que "la violencia policial se da más frecuentemente en las acciones contra los agronegocios" ${ }^{\prime(21)}$. En su Informe, la Relatora Especial de Naciones Unidas sobre el derecho a la alimentación acerca de su misión el Paraguay, da cuenta de este hecho: "A la Relatora Especial le preocupa que sigan teniendo lugar desalojos forzosos de comunidades campesinas y comunidades indígenas en diferentes partes del país. En la mayoría de los casos, estos desalojos se ejecutan con el uso de violencia por parte de seguridad estatal o privada" ${ }^{\prime(22)}$. El uso de la violencia incluye quema de viviendas, destrucción de cultivos, robos de bienes, entre otras prácticas.

En el mismo Informe, la Relatora igualmente señala: "La expansión del cultivo de soya en el Paraguay se ha visto acompañada por un uso excesivo de plaguicidas" ${ }^{(22)}$ y más adelante destaca: "La exposición a plaguicidas puede tener un impacto peligroso en la salud humana, siendo los niños y las niñas y las mujeres embarazadas particularmente vulnerables a sus efectos [...] Teniendo en cuenta la indivisibilidad de los derechos humanos, el impacto adverso de los plaguicidas, además de violar el derecho de acceso a alimentos adecuados y seguros, viola otros derechos humanos" ${ }^{\prime 22}$. Debe recordarse que en dos de los estudios referidos anteriormente, dicho impacto peligroso en la salud humana se expresaba en la presencia de daño genético en la población expuesta.

Desde el sistema penal también el Estado produce respuestas cuando las organizaciones campesinas reclaman por sus derechos. Particularmente, "la actuación de fiscales se reduce, lisa y llanamente, a la caza de cualquier disidente o grupo que pueda quebrantar o amenazar el negocio del modelo de producción dominante, ya que sus actuaciones carecen de racionalidad jurídico-penal y no se adecuan al modelo de persecución penal garantista diseñado en la Constitución de 1992" (23).

Para el caso de una de las poblaciones estudiadas, se graficó la cadena de violaciones de derechos humanos del siguiente modo, ver Figura 1:

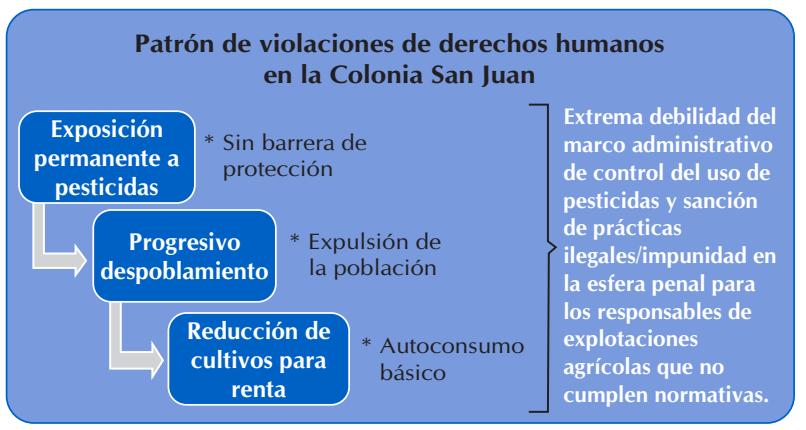

Figura 1. Patrón de violaciones de derechos humanos en la Colonia San Juan.

Se señala que este patrón de violaciones de derechos humanos no es una particularidad de la Colonia San Juan. Otras investigaciones locales constatan similar cadena de situaciones en otras comunidades afectadas por el agronegocio en Paraguay ${ }^{(24,25)}$; asimismo, a nivel regional, los conflictos registrados en las últimas décadas en Latinoamerica, comparten el mismo patrón ${ }^{(26,27,28,29)}$.

En ese sentido, la reducción de cultivos para renta registrada en la Colonia San Juan, configura otro hecho que se reitera en otros departamentos en los que el agronegocio se ha expandido. Los siguientes gráficos describen dicha situación:

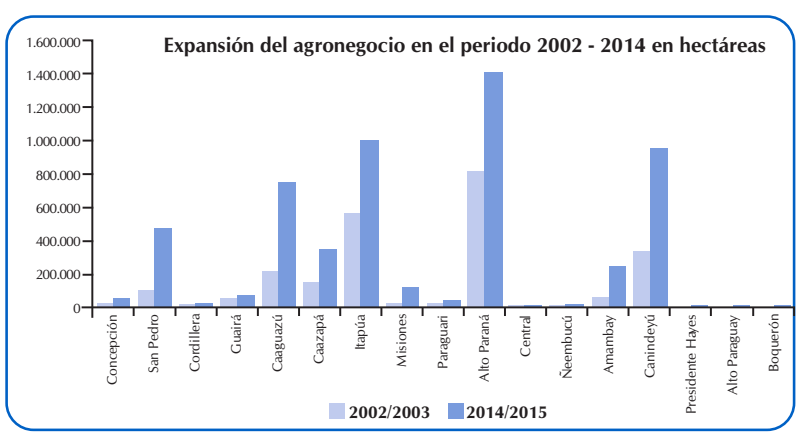

Figura 2. Expansión del agronegocio en el periodo 2002-2004 en hectáreas. Reproducido de Guillermo Ortega: Mapeamiento del Extractivismo. BASE-IS. Asunción, 2016 $6^{(30)}$. 


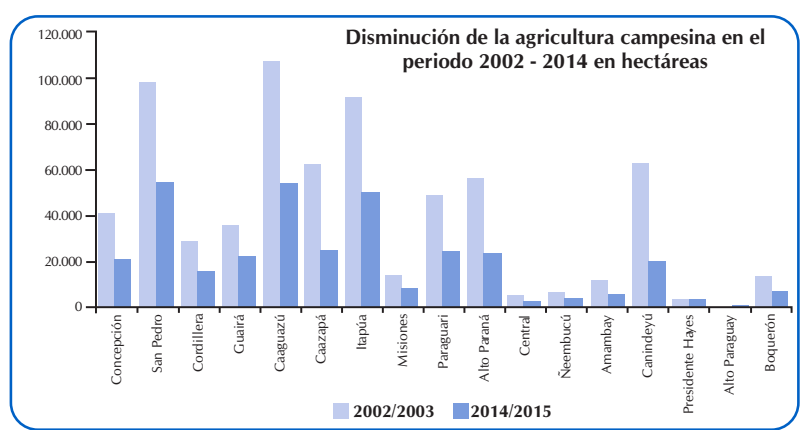

Figura 3. Disminución de la agricultura campesina en el periodo 2002-2004 en hectáreas. Reproducido de Guillermo Ortega: Mapeamiento del Extractivismo. BASE-IS. Asunción, 2016 ${ }^{(30)}$.

Se observa, ver Figura 2, así que en el mismo período en que se registra una expansión del agronegocio, se produce una disminución de la agricultura campesina lo que implica reducción progresiva de la base material para la reproducción del modo de vida campesino. Una investigación constata al respecto que en un periodo de seis años (2002 al 2008), la agricultura campesina perdió más de 38 mil fincas y en superficie más de 613 mil hectáreas, quedando así la migración como alternativa, ante el cierre de la colonización y el considerable incremento del valor de la tierra ${ }^{(31)}$. Esta merma en la producción campesina como consecuencia de la disminución en la superficie cultivada y el crecimiento sostenido del agronegocio, también es constatada en otro estudio ${ }^{(32)}$.Se menciona que la dignidad humana supone la autonomía o posibilidad de diseñar un plan vital y determinarse según las características propias; implica también ciertas condiciones materiales concretas de existencia y la seguridad del respeto a la integridad física e integridad moral. Es desde esta perspectiva que los daños que afectan a las vidas de las poblaciones mencionadas en los estudios referidos, son daños que envilecen la dignidad humana y destruyen, al mismo tiempo, la cultura humana que les otorga sentido, ver Figura 3.

\section{LOS LÍMITES MORALES DEL MERCADO}

¿Por qué, entonces, el modelo no sólo persiste sino que sigue expandiéndose? Gudynas destaca que una parte importante de las defensas del modelo se basa en argumentos económicos. "Se subrayan especialmente los ingresos por las exportaciones e inversiones, los impuestos y las regalías, y desde allí, por efectos derrames sobre las economías nacionales. Por tanto, el núcleo de argumentación exhibe a estos emprendimientos como aportes fundamentales para el crecimiento económico, y que este a su vez representa la esencia del desarrollo"(26).

Frente a esta visión, Satz plantea que "resulta evidente que la eficiencia no es el único valor relevante a la hora de examinar los mercados: también debemos tener en cuenta los efectos de estos sobre la justicia social, sobre nuestro modo de ser y de relacionarnos con los demás, y sobre el tipo de sociedad con que podemos contar" y esto es así porque fundamentalmente "algunos mercados malogran capacidades humanas deseables, otros influyen sobre las preferencias de la población de manera problemática y algunos de ellos fomentan la existencia de relaciones jerárquicas objetables entre las personas" ${ }^{\prime(33)}$.

Desde los principios de una Cultura de Paz, se asume como obligación el considerar los argumentos económicos que defienden el modelo de agronegocio como razones discutibles porque "para evaluar mercados, debemos tener en cuenta no sólo la producción y distribución de bienes, sino también las relaciones sociales y políticas que los distintos mercados sostienen y fomentan, incluidos sus efectos en pobres y ricos, hombres y mujeres, y más o menos poderosos. Tenemos que analizar cómo influyen los diversos mercados en las normas sociales que rigen nuestras interrelaciones personales" ${ }^{\prime(33)}$. Al respecto, además de la violencia que se configura como una condición necesaria del modelo de agronegocio, también la corrupción (soborno a órganos de control, de justicia y a la prensa, financiamiento de campañas electorales, etc.) surge como otra dimensión del mismo porque "existen fuertes vínculos -estructurales y perversos- de retroalimentación mutua entre todos estos procesos" ${ }^{\prime(34)}$.

Los estudios mencionados al inicio describen, en este sentido, un panorama en el que ninguno de los principios de una Cultura de Paz tienen cabida porque el mercado definido por los agronegocios atenta contra valores humanos fundamentales. Es siguiendo esta lógica que la Relatora Especial sobre el derecho a la alimentación, destaca en su Informe anual que "si bien los esfuerzos por prohibir y 
regular adecuadamente el uso de plaguicidas son un paso necesario en la dirección correcta, el método más eficaz a largo plazo para reducir la exposición a estos productos químicos tóxicos es abandonar la agricultura industrial”"(35). Señala, además, que "hoy en día el modelo agrícola dominante resulta sumamente problemático, no solo por el daño que causan los plaguicidas, sino también por los efectos de estos en el cambio climático, la pérdida de diversidad biológica y la incapacidad para asegurar una soberanía alimentaria [...] Es necesaria voluntad política para reevaluar y hacer frente a los intereses particulares, los incentivos y las relaciones de poder que mantienen en pie la agricultura industrial dependiente de productos agroquímicos. Deben cuestionarse tanto las políticas agrícolas como los sistemas de comercio y la influencia de las empresas en las políticas públicas si se quiere abandonar los sistemas industriales de alimentación dependiente de plaguicidas" ${ }^{\prime(35)}$.

\section{PERSPECTIVAS PARA UNA CULTURA DE PAZ Y UNA EDUCACIÓN PARA LA PAZ}

Actualmente el tema de la vida posible, para el caso de las poblaciones afectadas por la expansión del agronegocio en Paraguay, se enmarca en el siguiente contexto: "La estructura productiva en la actualidad tiene al sistema agroindustrial con orientación exportadora, el núcleo fundamental de la acumulación y concentración, limitando la ampliación del mercado interno y avanzando en la expulsión de la población rural" ${ }^{\text {(36) }}$.

Este contexto impone de forma violenta y cruel un modo de vida que se despliega a condición de que otros modos sean expulsados. Recordemos que, conforme a Mélich, "la crueldad es una manera de pensar, de normalizar, de vivir y de ser. No es un mero acto de violencia o de destrucción sino, sobre

\section{REFERENCIAS}

1. Benitez-LeiteS, Macchi ML, Acosta M. Malformaciones congénitas asociadas a agrotóxicos. Pediatr (Asunción). 2007;34(2):111-121. todo, una forma de vida, una forma de ordenar la vida, un modo-de-ser" ${ }^{\prime(37)}$. El otro expulsado, esas ciertas vidas que no califican como vidas - conforme el planteo de Butler-, queda fuera del ámbito de inmunidad del modo cruel y por ello resulta lógico que se violen de manera impune sus derechos. Y esta situación configura la contracara de una Cultura de Paz. La violación de sus derechos es probable que no se registre como tal ante la existencia de procesos jurídico-políticos que la permiten y naturalizan en tanto constituyen un doble régimen jurídico para quien está incluido y quien está excluido; el excluido se configura como no-persona, categoría que designa a "aquellos seres humanos que intuitivamente son personas como nosotros (seres humanos vivos dotados de una persona social y cultural), pero a los que le son revocadas - de hecho y de derecho, implícita o explícitamente, en las transacciones ordinarias o en el lenguaje público- la calificación de persona y sus atribuciones relativas" ${ }^{\prime 38}$.

¿Qué desafíos supone esto para un proceso de Educación para la Paz? Lo básico es asumir posicionamientos específicos acerca de las implicancias de un modo de producir, de concebir la economía, la sociedad que se organiza al margen del reconocimiento de los Derechos Humanos.

Es clave este punto de partida porque el consenso fundamental que sostiene la Declaración Universal de los Derechos Humanos es la siguiente afirmación: Todos los seres humanos son personas y deben ser tratados como tales. Desconocer este acuerdo básico mediante argumentos estrictamente económicos y de eficiencia de gestión, implica construir sociedades cada vez más lejanas de una Cultura de Paz.

¿Por qué se debería seguir llamando Sociedad a las mismas?
2. Benítez-Leite S, Macchi ML, Fernández V, Franco D, Ferro EA,Mojoli A, et al. Daño celular en una población infantil potencialmente expuesta a pesticidas. Pediatr (Asunción).2010;37(2):97-106. 
3. Benítez-Leite S, Corvalán R, Avalos DS, Almada M, Corvalán A. 2016. Violated rights in rural populations exposed to transgenic soybean crop (Preliminary Study).BJMMR. 2016;16(6):1-8. doi:10.9734/BJMMR/ 2016/25485

4. Arellano García ME, Camarena OjinagaL, Von-Glascoe CA, Ruiz Ruiz B, Zúñiga Violante E, Montaño Soto T. Daño genotóxico en mujeres y hombres expuestos en cuatro localidades de Baja California. En: Género, ambiente y contaminación por sustancias químicas. México: Secretaría de Medio Ambiente y Recursos Naturales (SEMARNAT) Instituto Nacional de Ecología;2012. p. 95-113.

5. Benachour N, Séralini G. Las formulaciones de glifosato inducen apoptosis y necrosis en células umbilicales, embrionarias y placentarias humanas.Investigación Química en Toxicología. 2009;22(1);97-105.

6. Gentile N, Bernardi N, Bosch B, Mañas F, Aiassa D. Estudios de genotoxicidad en trabajadores rurales $\mathrm{y}$ familias. Rev Cubana InvestBioméd. 2006;35(3):228-239.

7. Gómez-Arroyo S, Martínez-Valenzuela C, CarbajalLópez Y, Martínez-Arroyo A, Calderón-Segura ME, Villalobos-Pietrini R, et al. Riesgo genotóxico por la exposición ocupacional a plaguicidas en américa latina. Rev IntContamAmbie. 2013;29 (Número especial sobreplaguicidas):159-180.

8. Koller VJ, Furhacker M, Nersesyan A, Misik M, Eisenbauer M, Knasmueller, S. Cytotoxic and DNAdamaging properties of glyphosate and Roundup in human-derived buccal epithelial cells. Arch Toxicol.2012;86(5):805-813.

9. Mesnage R, Bernay B, Séralini GE. Ethoxylated adjuvants of glyphosate based herbicides are active principles of human cell toxicity. Toxicology. 2013;313:122-128.

10. Richard S, Moslemi S, Sipahutar H, Benachour N, Seralini GE. Differential effects of glyphosate and roundup on human placental cells and aromatase. Environ Health Perspect. 2005;113(6):716-720.

11. IARC (International Agency for Research on Cancer). Some drinking-water disinfectants and contaminants, including arsenic. IARC MonogrEvalCarcinog Risk Hum. 2004;84:1-442.

12. IARC (International Agency for Research on Cancer). Some organophosphate insecticides and herbicides. IARC MonogrEvalCarcinog Risk Hum. 2017;112:1-464.

13. Bolognesi C,Holland N. The use of the lymphocyte cytokinesis-block micronucleus assay for monitoring pesticide-exposed populations. Mutat Res.2016;770(Pt A):183-203.

14. Thongprakaisang S, Thiantanawat A, Rangkadilok N, Suriyo T, Satayavivad J. Glyphosate induces human breast cancer cells growth via estrogen receptors. Food ChemToxicol.2013;59:129-136.

15. SéraliniGE, Clair E, Mesnage R, Gress S, Defarge N, Malatesta M, et al. Republished study: long-term toxicity of a Roundup herbicide and Roundup-tolerant genetically modified maize. Environ Sci Eur. 2014;26(1):14.

16. Guyton KZ, Loomis D, Grosse Y, El Ghissassi F, Benbrahim-Tallaa L, Guha N. et al. Carcinogenicity of tetrachlorvinphos, parathion, malathion, diazinon, and glyphosate. Lancet Oncol. 2015;16(5):490-491.

17. Samsel A, Seneff S. Glyphosate, pathways to modern diseases IV: cancer and related pathologies. J BiolPhysChem. 2015;15(3):121-159.

18. Movimiento de Educadores por la Paz. Cultura de Paz: material de apoyo para maestros y estudiantes de Formación Docente. Uruguay: Consejo de Educación Inicial y Primaria; 2012.

19. RódenasUtray P. De las sociedades bélicas a las sociedades justas. En: Quesada F. Coordinador. Paz para la paz: Prolegómenos a una filosofía contemporánea sobre la guerra. Barcelona: Horsori editorial; 2014 p. 333-366.

20. Butler J. Marcos de guerra: Las vidas lloradas. Argentina: Paidós; 2010.

21. Areco A, Palau M. Judicialización y violencia contra la lucha campesina. Asunción: Base Investigaciones Sociales-Misereor; 2016.

22. Naciones Unidas. A/HRC/34/48/Add.2 Asamblea General Informe de la Relatora Especial sobre el derecho a la alimentación acerca de su misión al Paraguay. Internet. Ginebra: Naciones Unidas; 2017. Citado el 06 de junio del 2017. Recuperado a partir de: https://documentsddsny.un.org/doc/UNDOC/GEN/G17/019/76/PDF/G1701 976.pdf?OpenElement

23. Martens J, Aguayo E, López X, Orrego R. Disciplinamiento social y protección al agronegocio. Asunción: INECIP; 2015.

24. Fukuoka MP. Ciudadanía de papel: Derechos Humanos en comunidades campesinas. Asunción: Base Investigaciones Sociales-Observatorio DESCCooperación Española; 2015.

25. Fukuoka MP. Derecho a la alimentación en la 
administración Cartes. Asunción: Base Investigaciones Sociales; 2014.

26. Gudynas E. Sustentación, aceptación y legitimación de los extractivismos: múltiples expresiones pero un mismo basamento. Internet. Opera. 2014; 14:137-159. Citado el 06 de julio de 2017. Recuperado a partir de: http://www.reda lyc.org/articulo.oa? $i d=67540024007$

27. Gudynas E. Conflictos y extractivismos: conceptos, contenidos y dinámicas. Internet. DECURSOS. 2014;2728:79-115. Citado el 06 de julio de 2017. Recuperado partir de: https://horizontescomunitarios.files.wordpress.com/ 2016/09/gudynas-conflictosextractrivismosconceptos decs14.pdf

28. Gudynas E. Cuando los extractivismos reconfiguran democracias y derechos: tensiones y contradicciones bajo el progresismo realmente gobernante. Internet. Herramienta. 2014;54:139-150. Citado el 06 de julio de 2017. Recuperado a partir de: http://www.herramienta.com.ar/revistaherramienta-n-54/cuando-los-extractivismosreconfiguran-democracias-y-derechos-tensiones-y-c

29. Gudynas E. Extractivismos en América del Sur y sus efectos derrame. Internet. La Revista Boletín. 2015;76:1323. Citado el 06 de julio de 2017. Recuperado a partir de: http://accionyreaccion.com/wp-content/uploads/2016/07/ GudynasExtractivismosEfectosDerrameSSA2016.pdf

30. Ortega G. Mapeamiento del extractivismo. Asunción: Base Investigaciones Sociales-Fundación Rosa Luxemburgo; 2016.

31. Riquelme Q, Vera E. Agricultura campesina, agronegocio y migración: el impacto de los modelos de producción en la dinámica de los territorios. Asunción: Centro de Documentación y Estudios; 2015.

32. Benítez G. Agricultura familiar: ODM y gasto público. Asunción: Observatorio Fiscal-CADEP; 2016.

33. Satz D.¿Por qué algunas cosas no deberían estar en venta?: Los límites morales del mercado. Argentina: Siglo XXI; 2015.

34. Acosta A, Cajas-Guijarro J. Cruda realidad:corrupción, extractivismos, autoritarismo, rebelión. Internet. 2017; Citado el 06 de julio de 2017. Recuperado a partir de: http://www.rebelion.org/docs/230588.pdf

35. Naciones Unidas. A/HRC/34/48 Asamblea General: informe de la Relatora Especial sobre el derecho a la alimentación. Consejo de Derechos Humanos $34^{\circ}$ período de sesiones 27 de febrero a 24 de marzo de 2017; 2017.

36. Ortíz L. Apuntes para el estudio de las clases en la sociedad paraguaya. En: Ortíz L. Coordinador. Desigualdad y clases sociales: estudios sobre la estructura social paraguaya. Asunción: CLACSO Instituto de Ciencias Sociales-Centro de Estudios Antropológicos de la Universidad Católica; 2016. p. 239-298.

37. Mélich J-C. Lógica de la crueldad. Barcelona: Herder; 2014.

38. Dal Lago A. Personas y no-personas. En: Silveira Gorski HC. Editor. Identidades comunitarias y democracia. Madrid: Editorial Trotta; 2000. p. 127-144. 